\title{
Effect of Longitudinal Slope on Flow Pattern in a Doubly Meandering Compound Channel
}

\author{
G.M. Tarekul Islam *, Yoshihisa Kawahara ** and Nobuyuki Tamai*** \\ * Member, PhD, Visiting Researcher, Division of Social and Envrn. Eng., Graduate School of Eng., Hiroshima University \\ (1-4-1 Kagamiyama, Higashi-Hiroshima, Hiroshima 739-8527) \\ **Member, Dr. of Eng., Professor, Division of Social and Envrn. Eng., Graduate School of Eng., Hiroshima University \\ (1-4-1 Kagamiyama, Higashi-Hiroshima, Hiroshima 739-8527) \\ ***Member, Dr. of Eng., Professor, Division of Civil and Envrn. Eng., Graduate School of Science and Technology, Kanazawa \\ University (Kakuma-machi, Kanazawa, Ishikawa 920-1192)
}

\begin{abstract}
Natural rivers, being predominantly meandering, are usually composed of a deep main channel and adjacent shallow floodplains. This results in a meandering compound channel. When the main meander channel is flanked by floodplains with meandering levee, it results in a doubly meandering compound channel. This paper explores the effect of bed slope on flow pattern in a doubly meandering compound channel. The effect of slope on the exchange of momentum between main channel and floodplain, flow patterns in the transverse and longitudinal direction, difference in magnitude between maximum and minimum velocities, retardation and deviation of flow fields, the position and strength of eddies and augmentation and reduction of the main channel discharge has been discussed.
\end{abstract}

Key Words: Longitudinal slope, flow pattern, doubly meandering, compound channel

\section{Introduction}

Natural rivers are predominantly meandering. For the purpose of flood control, navigation and environmental conservation, it is a common practice to build embankments on both sides of the channel which results in a meandering compound channel. The outer levees or embankments can be straight or meandering. When the flond control embankments are meandering in shape, it results in a doubly meandering compound channel. That means a doubly meandering compound channel is one in which both upper and lower channels meander. In case of doubly meandering compound channel, the outer levee can be in phase with the main meander channel or there can be a phase difference between main channel and the floodplain. The phase difference is positive when the meandering outer levee is ahead of main channel and negative when it lags behind the main channel. Research has shown that the flow structure is complex, even for straight compound channels. The mechanisms are more difficult to analyze for compound meandering channel due to an increase in the three-dimensional nature of the flow and the interaction between the flow in the main channel and that in the floodplain. The insight in flow distribution between meandering main channel and adjoining floodplains is essential in river and floodplain management.

A study by Toebes and Sooky ${ }^{1)}$ was amongst the first to measure velocity distribution in both main channel and floodplains. They attempted to relate energy loss to observed internal flow structures associated with interaction between main channel and floodplains flows. They emphasized the importance of helicoidal channel flow and the shear at the horizontal interface between channel main and floodplain flows. They found that helicoidal currents in a meandering floodplain geometry were strikingly different from and more pronounced than those occurring in a meander channel carrying in-bank flow. Kiely ${ }^{2)}$ performed experiments with various values of relative depth and described the characteristics of compound meandering channel flows. He observed that the longitudinal floodplain flow impinges onto the deep main channel flow, leading to flow expansion, on the other hand, the flow over the main channel encounters an abrupt rise on re-entering the floodplain, causing flow contraction. Willets and Hardwick ${ }^{3)}$ demonstrated that channels of compound cross-section produce results which are distinctly different from those obtained in corresponding channels with more natural bed geometry. They also concluded that the transverse flows in natural bends are quite different when accompanied by over-bank flow from those 
frequently recognized for in-bank flow. Ishigaki et al. ${ }^{4)}$ investigated the flow structure in a meandering compound channel with experimental results by flow visualization and bed shear measurement. They concluded that for small relative depth, in-bank flow affects the whole flow structure. For large relative depth, over-bank flow runs straight and the flooding fluid from main channel is moved on the both sides of the channel. Muto et al. ${ }^{5}$ studied the three-dimensional flow structure in meandering channels during flood based on the velocity measurements by 2-component fiber optic laser Doppler anemometer. The growth and decay process of secondary flow cells in meandering channels and their differences between before and after inundation were investigated. Sellin et al. ${ }^{6)}$ studied the flow structures in meandering over-bank flow. They found that the floodplain flow approaches the main channel flow and becomes partly entrained into the main channel flow as well as driving a large scale secondary cell, which grows in width along the cross-over length. Jayaratne ${ }^{7}$ studied the three-dimensional flow characteristics of meandering compound channels.

The above studies were based meandering compound channel with straight floodways. Many researches have been conducted to understand the complicated flow structures in compound meandering channel with straight floodplain. But little is known about the flow structures in a doubly meandering compound channel. The flow structures become even more complex when there is a difference in phase between alignments of main channel and that of outer levees. Kinoshita ${ }^{8)}$ made experiments focusing on the phase difference between the main channel alignment and the levee alignment. He investigated the effects of the phase shift on the meandering channel flows from standpoint of surface velocity and bed evolution. Fukuoka and Ohgushi" ${ }^{\text {) }}$ studied the effect of levee alignment on meandering compound channel flows. They studied two cases of flow which had different phase of meandering between levees and main channel. Dead water area was found in the first case, where the meandering of levee goes ahead of that of main channel. In the second case, where the meandering of levees goes behind, flow found to be occurred over the channel. This paper deals with the effect of longitudinal slope on steady flow pattern in a doubly meandering compound channel with phase shift.

\section{Experimental Setup}

The experiments were conducted in a tilting flume whose length, width and depth are $30 \mathrm{~m}, 1.5 \mathrm{~m}$ and $1 \mathrm{~m}$, respectively. The flume constructed with vinyl chloride was mounted on $2 \mathrm{~m}$ steal channel structures. The longitudinal gradient of the channel is adjustable with a jack and hinge and can be varied up to $5 \%$. The channel consists of a main channel flanked by meandering levee on both sides of the main channel. The outer levee which has the same sinuosity as of main meander channel has a phase difference of about $30^{\circ}$ ahead of main channel. The meanders are expressed as combinations of arcs and straight reaches. The flume consists of

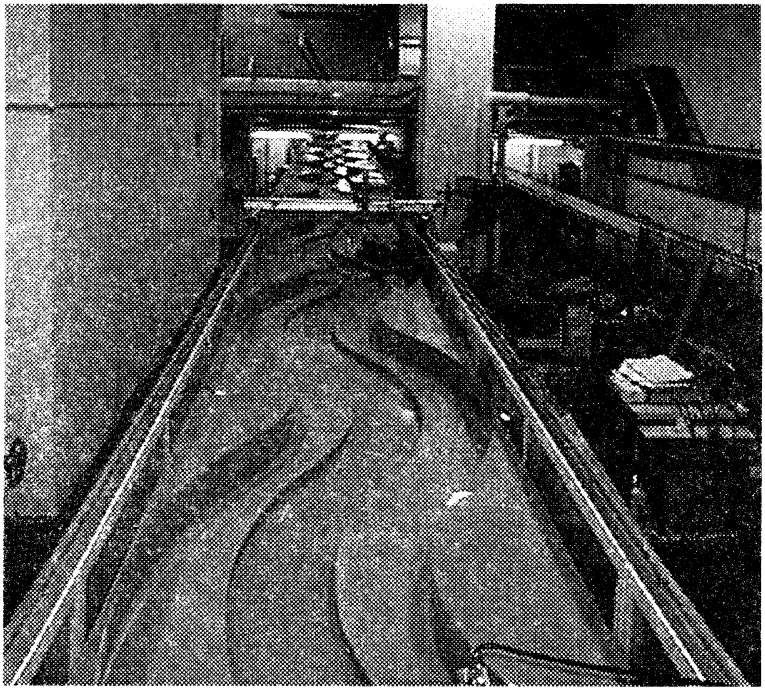

Fig.1 General layout of the experimental channel

nine consecutive meandering waves with straight approach channels at the beginning and end of the meandering part of the channel. The bed of the main channel and floodplains is smooth. Fig. 1 shows the general layout of the experimental channel. The details can be found in Islam ${ }^{10}$.

The water supply system in the channel is a closed one. From the downstream reservoir the water is transported by means of pipeline to the upstream reservoir. Consequently it flows to the experimental model and returns to the underground sump. Just next to the upstream reservoir is a rectangular weir of length $1.7 \mathrm{~m}$ and height $0.15 \mathrm{~m}$. This weir was used to measure the discharge. Although an electromagnetic flow meter connected to the delivery pipe measures the instantaneous discharge, the rectangular weir was used only to check the accuracy of the electromagnetic flow meter. A stilling basin attached to the upstream reservoir measures the height of the water depth over the rectangular weir by a point gauge mounted over the stilling basin.

A tailgate was set at the end of the channel. It is controlled up and down by an electric motor. It is used to obtain the uniform flow in the channel by adjusting the water surface slope by raising or lowering the tailgate. Two approach channels (length $=2.75 \mathrm{~m}$ ) have been placed at the beginning and end of the meandering compound channel. The approach channel is a straight compound channel having a main channel of cross-section of $0.30 \mathrm{~m} \times 0.05 \mathrm{~m}$ which is flanked by floodplain on both sides. This channel connects the meandering compound channel smoothly so that the flow can enter the main meandering channel without disturbance. Similarly the approach channel at the end provides smooth exit of the outgoing flow to the downstream reservoir through the end of the channel. The magnitudes of different geometric parameters are shown in Table 1.

For the study of the flow in a doubly meandering compound channel, the relationship between the alignment of the main channel and the levee is of great importance. The phase shift is defined as the difference between peak of the main channel bend and that of 
the floodplain in the longitudinal direction. More precisely, the phase shift is the ratio of the difference between the peak of the main channel bend and that of the meander flood levee to the wave length. The phase shift can be either positive or negative depending on the position of the meander levee. If the apex of the meander levee lies ahead of the bend apex of the main channel, then it is said to have a positive phase shift and vice versa. The phase shift of this doubly meandering compound channel is about $30^{\circ}$ ahead of the main channel.

Table 1 Geometric parameters

\begin{tabular}{|l|l|}
\hline \multicolumn{1}{|c|}{ Parameters } & \multicolumn{1}{c|}{ Dimension } \\
\hline \hline Meander wavelength & $\mathrm{L}_{\mathrm{w}}=2.720 \mathrm{~m}$ \\
Curved channel length & $\mathrm{L}=2.863 \mathrm{~m}$ \\
Cross-over length & $\mathrm{L}_{\mathrm{c}}=0.070 \mathrm{~m}$ \\
Phase difference & $\mathrm{L}_{\mathrm{d}}=0.229 \mathrm{~m}$ \\
Total width & $\mathrm{B}=0.800 \mathrm{~m}$ \\
Channel width & $\mathrm{b}=0.300 \mathrm{~m}$ \\
Height of floodplain & $\mathrm{h}=0.050 \mathrm{~m}$ \\
Sinuosity & $\mathrm{S}=1.05$ \\
Angle of arc & $\varphi=60^{\circ}$ \\
Main channel inner radius & $\mathrm{R}_{\mathrm{mi}}=1.150 \mathrm{~m}$ \\
Main channel outer radius & $\mathrm{R}_{\mathrm{mo}}=1.450 \mathrm{~m}$ \\
Flood levee inner radius & $\mathrm{R}_{\mathrm{f}}=0.900 \mathrm{~m}$ \\
Flood levee outer radius & $\mathrm{R}_{\mathrm{fo}}=1.700 \mathrm{~m}$ \\
\hline
\end{tabular}

\section{Instrumentation and Measurement}

For the measurement of water levels and velocities, the measuring probes were mounted on a carriage which traveled along the flume on a rail system. The carriage can be moved longitudinally to any desired position. The movement of the carriage in the transverse and vertical direction is automatically performed by electric motor which can be programmed to move the probe to the desired position. The accuracy of positioning of the measuring probe to the desired location is $0.1 \mathrm{~mm}$. The velocities were measured by two-component electromagnetic current meter. The I-type probe was used for measuring $\mathrm{x}$ - and $\mathrm{y}$-velocity components. The $\mathrm{x}$-velocity is in the direction normal to each cross section while the $y$-velocity is in the direction parallel to the cross section. The measuring time for velocity measurement was 40 seconds with a sampling frequency of $5 \mathrm{~Hz}$. The data were then averaged to get the point velocities. A point gauge was used to measure the channel bed elevations while a position meter was used to measure water surface. The mean depth was assumed to be the difference between the mean bottom and mean water surface elevations. The accuracy of the position meter was $0.1 \mathrm{~mm}$. An electromagnetic flow meter installed in the outflow pipe was used to measure the instantaneous discharge.

As the main channel meander is regular, the flow field is considered to be the same at positions in phase after the flow is fully developed. Thus the measuring reach has been selected at a distance of about $15 \mathrm{~m}$ from the beginning of the meander channel to ensure fully developed flow condition. The measurements were conducted over a measuring section of one wavelength i.e., $2.72 \mathrm{~m}$. The measuring reach has been divided into 9 sections (Fig. 2). The angle of arc between section 1 and 2 is $15^{\circ}$. Section 3 lies in the middle of the cross-over region. The angle of arc between section 4 and 5 is $15^{\circ}$ as well. The division of the sections is based on the main channel. The part of the section on the floodplain is normal to the longitudinal direction of the channel. Sections 1,5 and 9 are called as the bend apex sections while section 3 is the first cross-over section while section 7 is the second cross-over section.

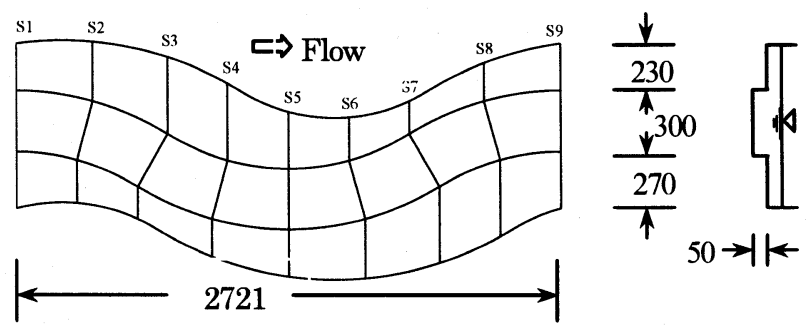

Fig.2 Measuring reach and different sections (dimensions in $\mathrm{mm}$ )

\section{Flow Conditions}

Two flow conditions were considered viz: shallow water condition and deep water condition. In shallow water condition, the average depth of flow over the floodplain is about $0.01 \mathrm{~m}$ whereas in deep water condition it is about $0.05 \mathrm{~m}$. The average depth of flow over the floodplain $0.05 \mathrm{~m}$ for deep water condition was selected by assuming that during flood the average depth of flow over the floodplain could be as high as the depth of bank-full flow i.e. the relative depth is 0.5 . To explore the effect of longitudinal bed slope on flow pattern, the experiments were conducted under two different longitudinal bed slopes of $1 / 1000$ and $1 / 350$. For brevity the bed slope of $1 / 1000$ is called mild and $1 / 350$ as steep. The flow conditions are summarized in Table 2.

Table 2 Flow conditions

\begin{tabular}{|l|l|l|l|l|}
\hline \multicolumn{1}{|c|}{ Slope } & \multicolumn{2}{c|}{$\begin{array}{c}\text { Mild slope } \\
(1 / 1000)\end{array}$} & \multicolumn{2}{c|}{$\begin{array}{c}\text { Steep slope } \\
(1 / 350)\end{array}$} \\
\hline \hline $\begin{array}{l}\text { Flow } \\
\text { conditions }\end{array}$ & Shallow & Deep & Shallow & Deep \\
\hline $\begin{array}{l}\text { Average } \\
\text { depth, H (cm) }\end{array}$ & 5.94 & 9.85 & 5.90 & 9.87 \\
\hline $\begin{array}{l}\text { Discharge, Q } \\
\left(\times 10^{-3} \mathrm{~m}^{3} / \mathrm{s}\right)\end{array}$ & 7.50 & 26.3 & 10.3 & 37.2 \\
\hline $\begin{array}{l}\text { Relative } \\
\text { depth, Dr }\end{array}$ & 0.156 & 0.492 & 0.153 & 0.493 \\
\hline $\begin{array}{l}\text { Mean } \\
\text { velocity, } \mathrm{U} \\
(\mathrm{m} / \mathrm{s})\end{array}$ & 0.326 & 0.479 & 0.479 & 0.676 \\
\hline $\begin{array}{l}\text { Reynolds } \\
\text { number, Re } \\
\left(\times 10^{4}\right)\end{array}$ & 0.813 & 2.60 & 4.70 & 14.8 \\
\hline $\begin{array}{l}\text { Froude } \\
\text { number, Fr }\end{array}$ & 0.658 & 0.652 & 0.951 & 0.920 \\
\hline
\end{tabular}

$\mathrm{Dr}=(\mathrm{H}-\mathrm{h}) / \mathrm{H}, \mathrm{U}=\mathrm{Q} / \mathrm{A}, \mathrm{Re}=4 \mathrm{RU} / \mathrm{v}, \mathrm{Fr}=\mathrm{U} / \sqrt{ }(\mathrm{gR})$; where $\mathrm{A}=$ cross-sectional area, $\mathrm{R}=$ hydraulic radius, $\mathrm{v}=$ kinematic viscosity and $\mathrm{g}=$ gravitational acceleration . 


\section{Effect of Slope on Flow Pattern under Shallow Water Condition}

Fig. 3 shows the stream-wise velocity distribution along different sections for shallow water condition under mild and steep slope at vertical distance $(\mathrm{z})$ of $0.01 \mathrm{~m}, 0.03 \mathrm{~m}$ and $0.04 \mathrm{~m}$ and $0.05 \mathrm{~m}$ from the main channel bed, respectively. The stream-wise velocity is the resultant of the $\mathrm{x}$-velocity $(\mathrm{u})$ and the $y$-velocity $(\mathrm{v})$.
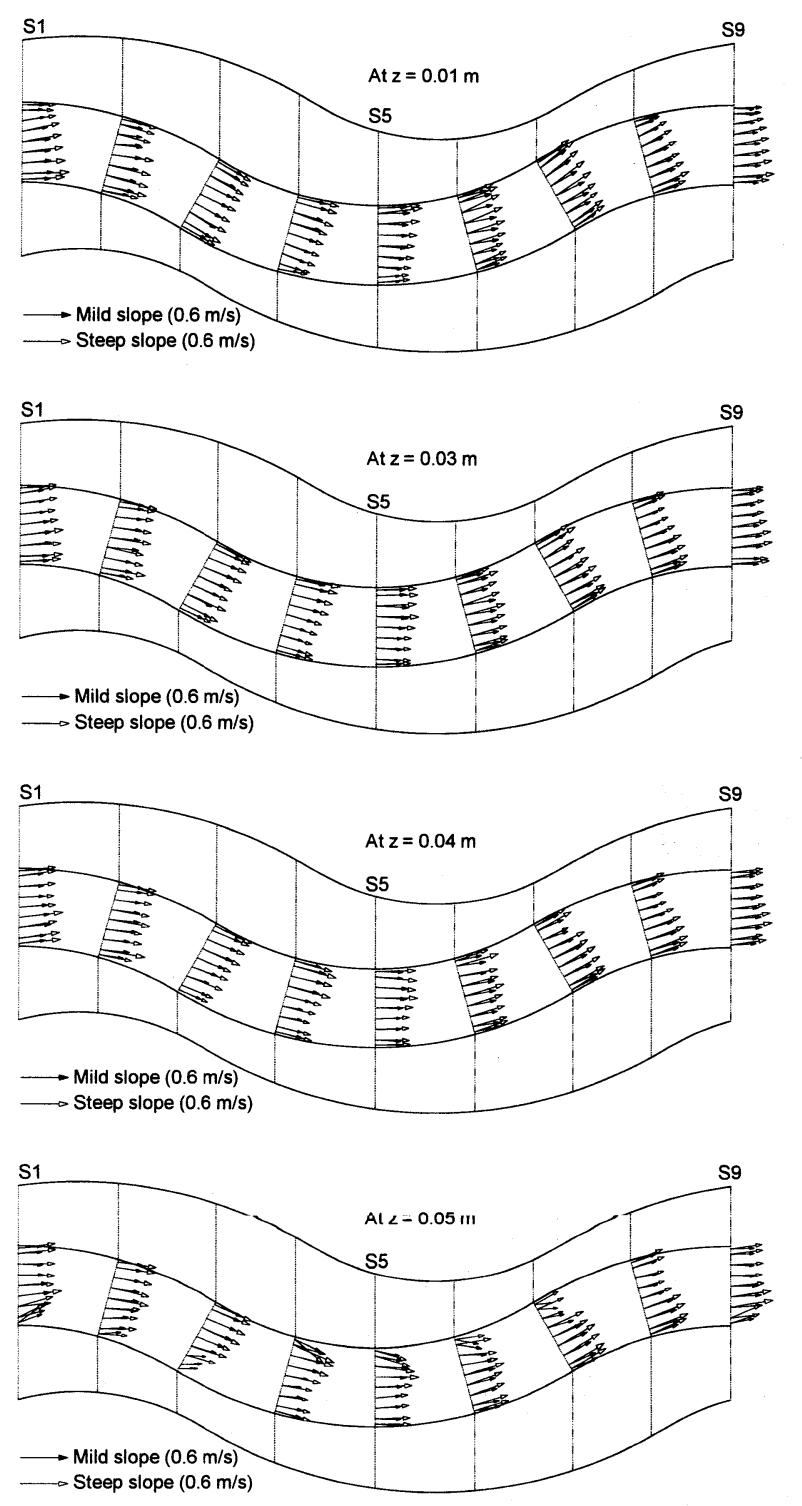

Fig.3 Stream-wise velocity distribution for deepwater condition $(\mathrm{Dr}=0.15)$

The flow fields at the bend apex section (sections 1 and 9) at $z$ of $0.01 \mathrm{~m}$ show that the maximum velocity occurs near the inner bank of the main channel while the minimum velocity occurs near the outer bank. This holds true for both mild and steep slope. However, it appears that at higher bed slope, the flow tends to move away from the inner bank of the main channel. This is due to the greater intensity of the impingement of the floodplain flow from the right floodplain to the main channel. This suggests that the intensity of flow impingement from right floodplain to the main channel at bend apex section is higher for higher bed slope. The flow patterns are the same at the next bend apex section (section 5) but in opposite orientation. Following the bend apex section at section 2, the flow fields show that the maximum velocity occurs near the inner bank of the main channel while the minimum velocity occurs near the outer bank. In this case, however, as compared to the bend apex section the position of the minimum velocity fields is moved towards the right bank of the main channel. This holds true for both mild and steep slope. However, it appears that at higher bed slope, the flow tends to move away from the inner bank towards the outer bank of the main channel. This can be attributed to the fact that the intensity of the impingement of the floodplain flow from the right floodplain to the main channel for higher bed slope has been reduced as compared to the bend apex section. The flow fields in the first cross-over section (section 3) follow the alignment of the main channel. This means that the flow fields are perpendicular to the section at the point of inflection where the curvature effect is non-existent. There is virtually no difference of flow pattern between mild and steep slope. This suggests that there is no effect of bed slope on flow pattern at the first cross-over region in a doubly meandering compound channel under shallow water condition. Following the cross-over region at section 4 , it can be seen that the maximum velocity occurs near the left bank while the minimum velocity ours near the right bank. This holds true for both mild and steep slopes. It appears that the flow fields under steep slope move towards the right bank as compared to those under mild slope. The flow pattem in the next cross-over section is however different as compared to that in the previous cross-over region. While the flow fields in section 3 follow the alignment of the main channel for both mild and steep slopes, the flow fields under steep gradient in section 7 move towards the left bank of the main channel as compared to mild gradient.

The transverse profiles of the flow fields are regular near the channel bed. At higher depth from the channel bed the transverse profiles lose its regularity and their irregularity becomes more pronounced. This suggests that the effect of the exchange of momentum between main channel and floodplain is less near the channel bottom than that at the floodplain level. The difference in magnitude of the stream-wise velocities near main channel bed is high at the bend apex section and low at the cross-over section for both mild and steep slopes. At the floodplain height, the difference in magnitudes of the stream-wise velocities is high at the cross-over section and low at the bend apex as opposed to the cases near the channel bed. At the bend apex section it is also seen that the deviation of the stream-wise velocity increases at higher depth and becomes maximum at the floodplain level which is subject to severe interaction between main channel and floodplain. Table 3 shows the stream-wise velocity and the angle of deviation at right bank under shallow water condition for bend apex and cross-over sections at floodplain level and near channel bed. The Table shows the extent of retardation of flow velocity and the angle deviation at floodplain level compared to channel bed. It can be seen that the extent of 
retardation is higher at higher bed slope. The maximum retardation occurs at the cross-over section for both mild and steep slopes. The angle of deviation is higher at higher bed slope. The angle of deviation is maximum at the cross-over section for mild slope and at the bend apex section for steep slope.

Table 3 Magnitude of stream-wise velocity $(\mathrm{V})$ and the angle of deviation $(\theta)$ under shallow water condition

\begin{tabular}{|l|c|c|c|c|c|}
\hline Section & \multirow{2}{*}{$\mathrm{H}(\mathrm{m})$} & \multicolumn{2}{|c|}{ Mild slope } & \multicolumn{2}{c|}{ Steep slope } \\
\cline { 3 - 6 } & & $\begin{array}{c}\mathrm{V} \\
(\mathrm{m} / \mathrm{s})\end{array}$ & $\begin{array}{c}\theta \\
(\mathrm{deg})\end{array}$ & $\begin{array}{c}\mathrm{V} \\
(\mathrm{m} / \mathrm{s})\end{array}$ & $\begin{array}{c}\theta \\
(\mathrm{deg})\end{array}$ \\
\hline \hline \multirow{2}{*}{$\begin{array}{l}\text { Bend apex } \\
\text { (Sec 1) }\end{array}$} & 0.50 & 32.3 & 19.5 & 40.3 & 35.2 \\
\cline { 2 - 6 } & 0.10 & 36.4 & 1.83 & 54.3 & 3.29 \\
\hline $\begin{array}{l}\text { Cross-over } \\
\text { (Sec 3) }\end{array}$ & 0.50 & 19.2 & 31.8 & 24.6 & 30.7 \\
\cline { 2 - 6 } & 0.10 & 35.7 & 1.77 & 49.3 & 1.00 \\
\hline
\end{tabular}

In the bend apex section, the width of the right floodplain gradually narrows down and the velocity filament tends to retard to the main channel from the floodplain which causes vigorous mixing of floodplain flow to the main channel flow. This mixing is high at the interface between main channel and floodplain at the right bank at the cross-over region where the width of the floodplain gets far narrower. The width of the right floodplain at the cross-over section gradually increases in the downstream direction until the next cross-over section is reached. Consequently, the degree of deviation of the velocity filament becomes weaker and follows the main channel alignment. On the other hand, the width of the left floodplain at the bend apex, gradually increases in the downstream direction until the cross-over is reached. This causes the main channel flow to enter into the floodplain. The opposite things happen in the next bend.

\section{Effect of Slope on Flow Pattern under Deep water Condition}

Fig. 5 shows the stream-wise velocity distribution along different sections for deep water condition under mild and steep slopes at $\mathrm{z}$ of $0.01 \mathrm{~m}, 0.03 \mathrm{~m}$ and $0.04 \mathrm{~m}, 0.05 \mathrm{~m}, 0.06 \mathrm{~m}, 0.07 \mathrm{~m}$ and $0.09 \mathrm{~m}$, respectively. The flow fields at the bend apex sections (sections 1 and 9) at a depth of $0.01 \mathrm{~m}$ from the main channel show that the maximum velocity occurs near the inner bank of the main channel while the minimum velocity occurs near the outer bank for both mild and steep slopes. However, it appears that at higher bed slope, the flow tends to move away from the inner bank of the main channel. This is due to the greater intensity of the impingement of the floodplain flow from the right floodplain to the main channel. This suggests that the intensity of flow impingement from right floodplain to the main channel at bend apex section is higher for higher bed slope. Following the bend apex section at section 2 , the flow fields show that the maximum velocity occurs near the inner bank of the main channel while the minimum velocity occurs near the outer bank. It appears that at higher bed slope, the overall flow direction makes an angle with those of mild slope towards the left bank of the main channel. This can be attributed to the fact that the intensity of the impingement of the floodplain flow from the right floodplain to the main channel for higher bed slope has been reduced as compared to the bend apex section. The flow fields near channel bed in the cross-over section (section 3) follow the alignment of the main channel. There is virtually no difference of flow pattern between mild and steep slope at lower depths in the first cross-over region (section 3 ) of the meander wave. However, there is significant difference between flow pattern of mild and steep slope at the next cross-over region of the second half of the meander wave. This suggests that the flow pattern is dissimilar in the two cross-over sections in a meander wave under mild and steep slope. While the flow fields near channel bed at the second bend apex section (section 7) under mild slope follow the main channel alignment as in the first bend apex, the flow fields under steep slope shift towards the left bank of the main channel. Following the cross-over region at section 4 , it can be seen that the maximum velocity occurs near the left bank while the minimum velocity ours near the right bank. This holds true for both mild and steep slopes. It appears that the flow fields under steep slope move a little towards the right bank as compared to those under mild slope. The flow fields at the next bend apex section (section 5) are of similar pattern as of section 1 but in opposite orientation. The flow pattern in the next cross-over section (section 7) is however different as compared to that in the previous cross-over region. While the flow fields in section 3 follow the alignment of the main channel for both mild and steep slopes, the flow fields under steep gradient in section 7 move towards the left bank of the main channel as compared to mild gradient.

The transverse profiles are regular near the channel bed. At higher depth from the channel bed the transverse profiles lose its regularity and their irregularity becomes more pronounced. This suggests that the effect of the exchange of momentum between main channel and floodplain is less near the channel bottom than that at the floodplain level. At the bend apex section it is also seen that the deviation of the stream-wise velocity increases at higher depth and becomes maximum at the floodplain level which is subjected to severe interaction between main channel and floodplain.

The difference in magnitudes between the maximum and minimum velocities gradually decreases until the cross-over section is reached. At higher depths the difference between maximum and minimum velocity is more pronounced and the degree of deviation increases. The expansion and contraction of longitudinal velocity occurs above the floodplain level. The longitudinal main channel flow in the outer bank of the bend apex section impinges onto the left floodplain, leading to contraction. The contraction is maximum in the left main channel-floodplain interface of section 2 while there is expansion of flow in the left floodplain. The interchange of flow between main channel and floodplain is now readily observable. The floodplain flow in the inner bank of section 1 enters the main channel whereas the main channel flow enters the left floodplain. The interchange appears to be high at the cross-over region. 

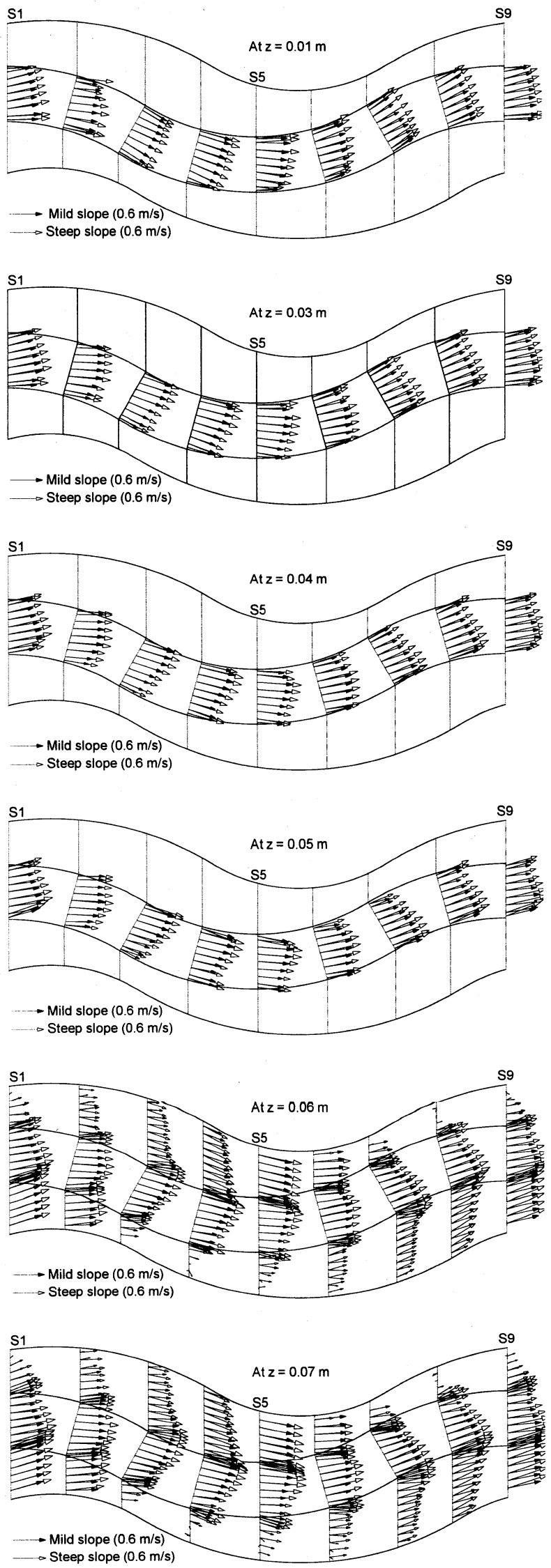

Fig.4 Stream-wise velocity distribution for deepwater condition $(\mathrm{Dr}=0.49)$

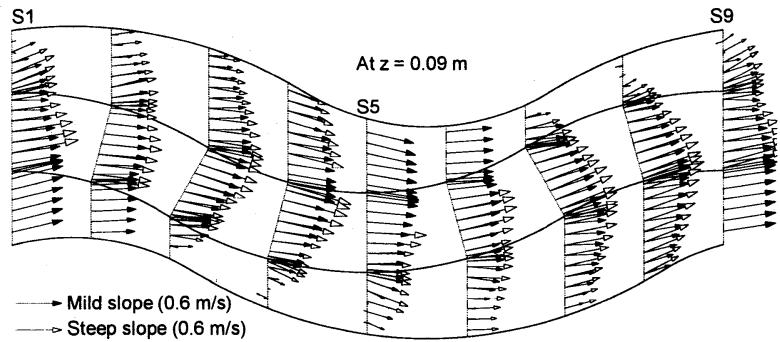

Fig.4 Stream-wise velocity distribution for deepwater condition $(\mathrm{Dr}=0.49)$ (Contd.)

Table 4 shows the stream-wise velocity and the angle of deviation at right bank under deep water condition for bend apex and cross-over sections at floodplain level and near channel bed. It can be seen that the extent of retardation is higher at higher bed slope. The maximum retardation occurs at the cross-over section for both mild and steep slopes. The angle of deviation is higher at higher bed slope. The angle of deviation is maximum at the cross-over section for mild slope and at the bend apex section for steep slope.

Table 4 Magnitude of stream-wise velocity $(\mathrm{V})$ and the angle of deviation $(\theta)$ under deep water condition

\begin{tabular}{|c|c|c|c|c|c|}
\hline Section & $\mathrm{H}(\mathrm{m})$ & \multicolumn{2}{|c|}{ Mild slope } & \multicolumn{2}{c|}{ Steep slope } \\
\cline { 3 - 6 } & & $\begin{array}{c}\mathrm{V} \\
(\mathrm{m} / \mathrm{s})\end{array}$ & $\begin{array}{c}\theta \\
(\mathrm{deg})\end{array}$ & $\begin{array}{c}\mathrm{V} \\
(\mathrm{m} / \mathrm{s})\end{array}$ & $\begin{array}{c}\theta \\
(\mathrm{deg})\end{array}$ \\
\hline \hline \multirow{2}{*}{$\begin{array}{c}\text { Bend apex } \\
\text { (Sec 1) }\end{array}$} & 0.50 & 54.4 & 15.9 & 70.7 & 21.2 \\
\cline { 2 - 6 } & 0.10 & 56.5 & 1.32 & 77.8 & 2.32 \\
\hline $\begin{array}{c}\text { Cross-over } \\
\text { (Sec 3) }\end{array}$ & 0.50 & 40.8 & 14.9 & 49.3 & 10.8 \\
\cline { 2 - 6 } & 0.10 & 43.7 & -0.58 & 60.1 & 1.18 \\
\hline
\end{tabular}

In the bend apex section, the width of the right floodplain

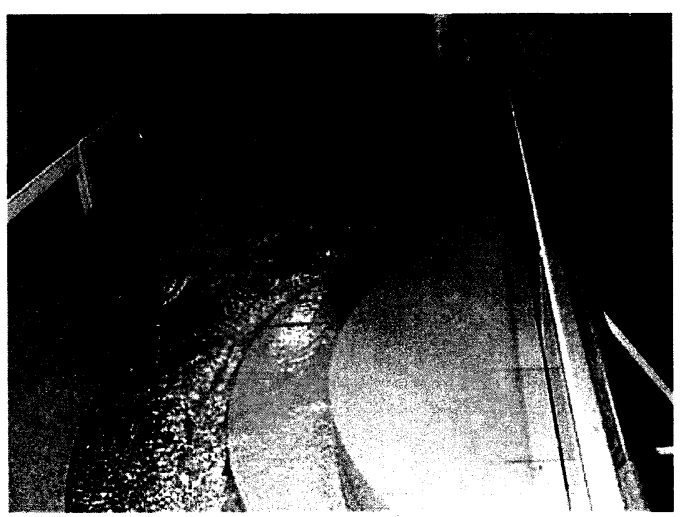

Fig. 5 Visualization of flow exchange showing floodplain flow entering the main channel

gradually narrows down and the velocity filament tends to retard to the main channel from floodplain which causes vigorous mixing of floodplain flow to the main channel flow. This can be clearly seen through flow visualization (Fig. 5). The mixing is high at the interface between main channel and floodplain at the right bank at the cross-over region where the width of the floodplain gets far narrower. The width of the right floodplain at the cross-over section gradually increases in the downstream direction until the next 
cross-over section is reached. Consequently, the degree of deviation of the velocity filament becomes weaker and follows the main channel alignment. On the other hand, the width of the left floodplain at the bend apex gradually increases in the downstream direction until the cross-over section is reached. This causes the main channel flow to enter into the floodplain. The opposite things happen in the next bend.

Islam et al ${ }^{11)}$ explored the effect of longitudinal slope on secondary flow structures in a doubly meandering compound channel. They found that in case of mild gradient, the anti-clockwise cell grows along the inner bank of the main channel, reaches its peak at a section in between the cross-over region and the bend apex next to the cross-over region and decays immediately upstream of the bend apex (Fig. 6a). But in case of steep slope, in addition to the anti-clockwise secondary cells developed along the inner bank of the main channel, the same type of cells also develop along the outer bank and grows until it reaches in a section in between the bend apex and the cross-over section (Fig.6b).

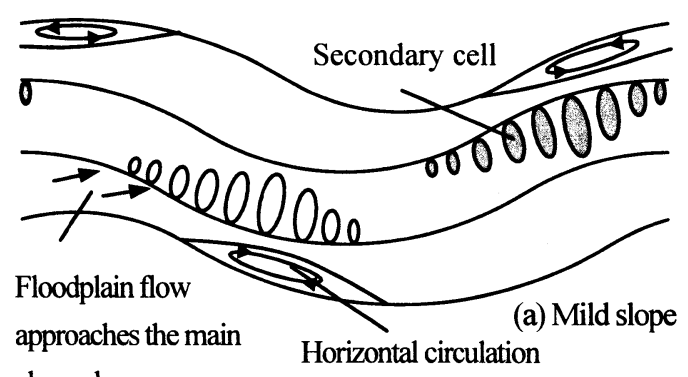
channel

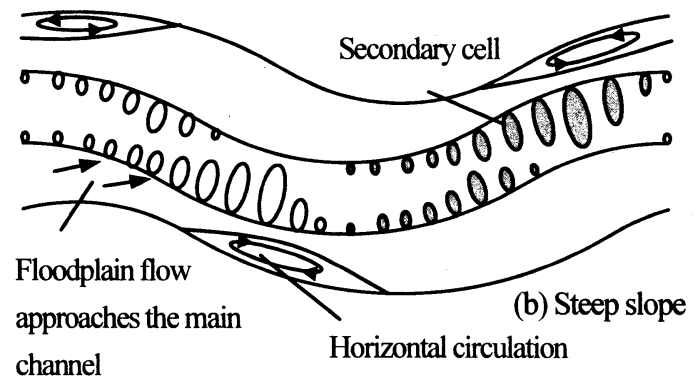

Fig. 6 Schematic diagram showing the evolution and decay process of secondary currents

It is seen that the stream-wise velocities in the bend apex sections and its upstream sections are negative near the outer levee. The width of the right floodplain immediately after the cross-over region widens in the downstream direction. The flow in this region behaves like a flow separation and thus causes the velocity filaments to reverse the direction near the levee wall. This circulation exists in about one-third of the meander wave. The size of the eddy is larger near the water surface than that near the floodplain bed. When the depth of water over the floodplain increases, the strength of this horizontal eddies diminish as the main flow dominates everywhere in the channel. The position and strength of these eddies also depend on the longitudinal bed slope. With higher bed slope, the horizontal eddies appear to suppress and confine to a position upstream of the bend apex.

\section{Effect of Slope on the Flow in the Main Channel}

Figs. 7 and 8 show the distribution of discharge in the main channel along different sections for both mild and steep slopes under shallow and deep water conditions, respectively. It is seen from Fig. 7 that there is augmentation and reduction of the main channel discharge along different sections. For mild slope, the augmentation of discharge occurs from section 1 to 3 whereas the reduction of discharge occurs from section 3 to 5 . But in case of steep slope, it is seen that the augmentation occurs from section 3 to 5 whereas the reduction occurs from section 1 to 3 . So there appears to have some phase difference in increment and decrement of the main channel discharge in shallow water condition. Regarding section 1 to 3 in shallow water condition, the amount of flow entering into the main channel is higher than that leaving

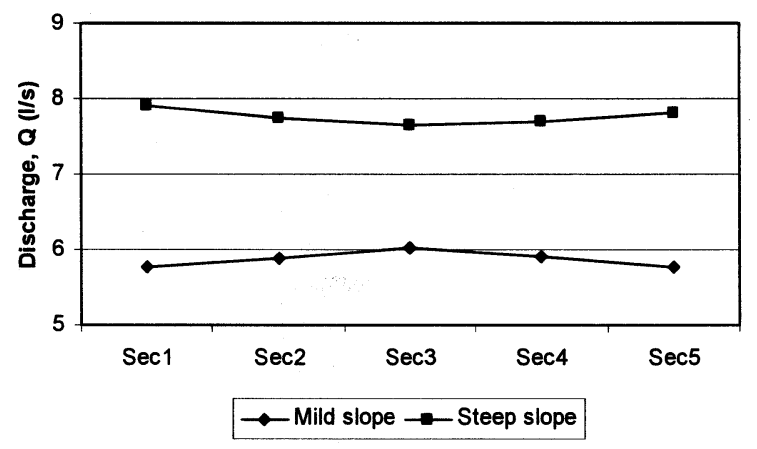

Fig.7 Distribution of discharge in the main channel along different sections for shallow water condition

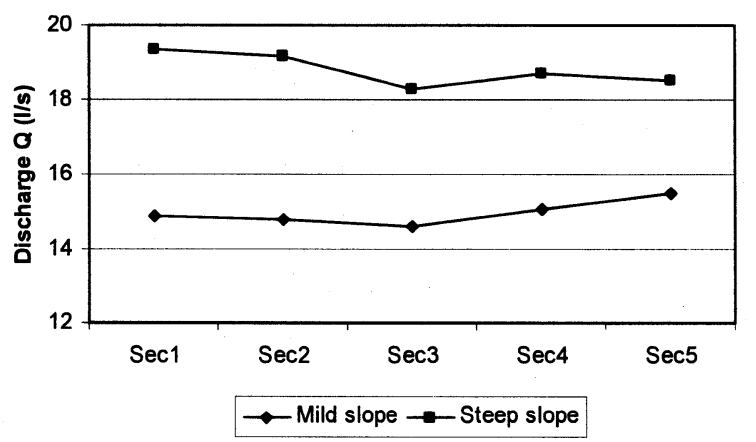

Fig.8 Distribution of discharge in the main channel along different sections for deep water condition

from main channel. As can be seen from seen Fig. 3 that the velocity filament in the inner bank is towards main channel and that in the outer bank is towards left floodplain. This implies that water enters the main channel from right floodplain and leaves from main channel to left floodplain. So the amount of flow entering into the main channel from right floodplain is higher than that leaving from main channel to the left floodplain. On the other hand in steep 
slope, the amount of flow entering the main channel from right floodplain is lower than that leaving from the main channel to the left floodplain. This suggests that the distribution of flow in the main channel is influenced by the longitudinal bed slope.

It is seen from Fig. 8 that there is augmentation and reduction of the main channel discharge along different sections. The augmentation of discharge occurs from section 3 to 5 whereas the reduction of discharge occurs from section 1 to 3 . Unlike shallow water condition, the flow distribution in the main channel for steep slope follows that of mild slope with the only exception at section 4 . In case of deep water condition, the main channel discharge decreases as the water flows from bend apex to the downstream direction until it reaches the cross-over section as opposed to shallow water condition. Regarding sections 1 to 3 in deep water case, the amount of flow entering the main channel is less than that leaving from main channel. It can be seen from Fig. 4 that the velocity filament in the inner bank is towards main channel and that in the outer bank is towards left floodplain. So the amount of flow entering into the main channel from right floodplain is less than that leaving from main channel to the left floodplain which is opposed to the shallow water condition.

\section{Conclusions}

This paper explores the effect of longitudinal slope on flow pattern in a doubly meandering compound channel with positive phase shift of about $30^{\circ}$. The effect of the exchange of momentum between main channel and floodplain is less near the channel bottom than that at the floodplain level for both mild and steep slopes. The flow patterns in the cross-over sections are different between mild and steep slopes. While the flow fields in first cross-over section follow the alignment of the main channel for both mild and steep slopes, the flow fields under steep gradient in the second cross-over section move towards the left bank of the main channel as compared to mild gradient. The exchange of flow between main channel and floodplain derives secondary cells which are different for mild and steep gradient.

The difference in magnitude between the maximum and minimum velocities near main channel bed is high at the bend apex section and low at the cross-over section for both mild and steep slopes. At the floodplain height, the difference in magnitudes of the stream-wise velocities is high at the cross-over section. The exchange of flow between main channel and floodplain results in retardation and deviation of flow velocity. The maximum retardation occurs at the cross-over section for both mild and steep slopes. The angle of deviation is higher at higher bed slope. The angle of deviation is maximum at the cross-over section for mild slope and at the bend apex section for steep slope.

Horizontal eddies are generated around a region in between the bend apex of the outer bank of the main channel and the side wall of the outer levee. The position and strength of these eddies depend on the longitudinal bed slope. With higher bed slope, the horizontal eddies appear to suppress and confine to a position upstream of the bend apex.

There is augmentation and reduction of the main channel discharge along different sections. For mild slope, the augmentation of discharge occurs from section 1 to 3 whereas the reduction of discharge occurs from section 3 to 5 . But in case of steep slope, the augmentation occurs from section 3 to 5 whereas the reduction occurs from section 1 to 3 . In case of deep water condition, the augmentation of discharge occurs from section 3 to 5 whereas the reduction of discharge occurs from section 1 to 3 . Unlike shallow water condition, the flow distribution in the main channel for steep slope follows that of mild slope with the only exception at section 4 .

\section{References}

1) Toebes, G.H., and Sooky, A.A., Hydraulics of meandering rivers with flood plains, Journal of the Waterways and Harbors Division, Proceedings of the American Society of Civil Engineers, 93, WW2, pp.213-236, 1967.

2) Kiely, G., Overbank flow in meandering compound channels: the important mechanisms, Ed. White, W.R., Wiley, Chichester, pp.207-213, 1990.

3) Willets, B.B. and Hardwick, R.I., Models studies of overbank flow in meandering channels, Proc. Institution of Civil Engineers, Water, Maritime and Energy, 101, pp.45-54, 1990.

4) Ishigaki, T., Muto, Y., Takeo, N. and Imamoto, H., Fluid mixing and boundary shear stress in compound meandering channel. $27^{\text {th }}$ Congress of LAHR, Sanfransisco, USA, pp.763-768, 1997.

5) Muto, Y., Shino, K., Imamoto, H., and Ishigaki, T., Three-dimensional flow structure for overbank flow in meandering channels, Journal of Hydroscience and Hydraulic Engineering, JSCE, 16(1), pp.97-108, 1998.

6) Sellin, R.H.J., Ervine, D.A., and Willetts, B.B., Behaviour of meandering two-stage channels, Proc. Instn Civ. Engrs, Water, Maritime. \& Energy, 101, pp.99-111, 1993.

7) Jayaratne, B.L., Three-dimensional flow structure in straight and meandering compound channels and planning of desirable river configuration, Ph.D. Dissertation, University of Tokyo, Japan, 1998.

8) Kinoshita, R., Experimental study concerning field work of alluvial phenomena at flooding and best possible river course example. Report of Scientific Research, pp.63-168, 1988.

9) Fukuoka, S., and Ohgushi, H., Effect of levee alignment on doubly meandering compound channel flows, Anmual Journal of Hydraulic Engineering, JSCE, 41, pp.1137-1140, 1997.

10) Islam, G.M.T., Three-dimensional flow fields in a doubly meandering compound channel under steady and unsteady flow conditions, Ph.D. dissertation, University of Tokyo, Japan, 2000.

11) Islam, G.M.T., Influence of longitudinal slope on secondary flow structures in a doubly meandering compound channel, $2^{\text {nd }}$ International Summer Symposium, JSCE, pp.161-164, 2000.

(Received: April 12, 2007) 